\title{
H3 Protein Variant
}

National Cancer Institute

\section{Source}

National Cancer Institute. H3 Protein Variant. NCI Thesaurus. Code C129311.

A variation in the amino acid sequence for the histone h3 protein. 